\title{
Band Keratopathy
}

National Cancer Institute

\section{Source}

National Cancer Institute. Band Keratopathy. NCI Thesaurus. Code C118765.

The deposition of calcium on the cornea, resulting in pain and decreased visual acuity. 